\title{
Assessment Challenges \& Impact of Formative Portfolio Assessment (FPA) on EFL Learners' Writing Performance: A Case Study on the Preparatory English Language Course
}

\author{
Md. Jahangir Alam ${ }^{1} \&$ Tahmina Aktar ${ }^{2}$ \\ ${ }^{1}$ Faculty of Languages \& Translation, King Khalid University, Kingdom of Saudi Arabia \\ ${ }^{2}$ Community College for Girls', King Khalid University, Kingdom of Saudi Arabia \\ Correspondence: Md. Jahangir Alam, Faculty of Languages \& Translation, King Khalid University, Abha, Saudi \\ Arabia.
}

Received: May 13, 2019 Accepted: June 20, 2019 Online Published: June 22, 2019

doi: $10.5539 /$ elt.v12n7p161 URL: https://doi.org/10.5539/elt.v12n7p161

\begin{abstract}
Present study aimed to explore the impact of formative portfolio assessment on Saudi EFL learners' overall writing performance. The study reviewed literature of prevailing assessment challenges including the formative role of portfolio assessments to develop an understanding of the nature of assessments and various issues related to assessment practices. The current research applied formative portfolio assessment (FPA) technique as an intervention material in the ongoing preparatory Intensive English Language course and utilized semi-structured interviews to elicit qualitative data from students. The findings of the study suggest: formative portfolio assessment inspires autonomous learning among students by empowering them taking more control of the learning and assessment process.
\end{abstract}

Keywords: assessment, formative, portfolio, Saudi EFL, writing performance

\section{Introduction}

In education, the term "assessment" refers to the wide variety of techniques or tools that teacher-educators use to evaluate learning progress or education needs of students. "Assessment is a central feature of teaching and the curriculum. It powerfully frames how students learn and what students achieve” (David Boud et al., 2010, p. 1). Traditionally, it means assessing learning of students'. However, because assessments play a very significant role in students' understanding, researchers suggested a paradigm shift of assessment from "testing learning of students to assessing for students learning" (Birenbaum \& Feidman, 1998, p. 92). There is widespread agreement that assessment is an integral part of any effective educational system but the debate about assessment-practices mainly centers on the challenges and complexities assessment poses in implementing it effectively. We will focus on this debate in Saudi EFL (English as a foreign language) context with a research objective of finding how effective the formative portfolio assessment is as an assessment technique.

\section{Assessment Practices in Saudi EFL Classroom}

Assessment can take a wide variety of forms in education. Wiliam and Thompson (2008), Scriven (1967) and Bloom (1969) proposed the terminology "formative" and "summative" assessment, with a view to distinguish the role of evaluation. The use of assessment for student learning is the main characteristic of formative assessment. This type of assessment is introduced as a continuous process of evaluating students' learning, providing feedback to adjust instruction, improving the curriculum. Summative assessments on the other hand are those assessments designed to determine a student's academic development after a set unit of material (Stiggins, 2002). A well-designed assessment practice has the potential not only to measure learning but also to motivate it to the next level of achievement. Recent research has also documented the benefits of regular use of diagnostic and formative assessments as feedback for teaching and learning (Black et al., 2004).

In Saudi EFL context, the scope and frequency of formative assessment is considerably low as it is observed by El Ebyary (2013): formative assessment has been overshadowed by summative assessment practices in more ways than one in the Middle East. Saudi curriculum is rigid and prescriptive with no opportunity for teachers to develop or amend them. However, classroom assessment constitutes a major component in the curriculum and 
syllabus design. The main modes of assessment here, being written assessments and structured oral assessments (Alhareth \& Dighrir, 2014). In Saudi Arabia, assessments come in the form of traditional (standardized) tests, which means that students usually do this type of test individually using paper and pencil to answer written questions which include gap fill, multiple choice, true or false and essays (Alsadaawi, 2010). It is evident that, in an English language course, classroom assessment constitutes a significant part of the assessment standard and there is ample scope of improvement in this area. Based on the various studies conducted in this field, following observation can be pointed ou: Language teachers lack training in teaching field and they depend largely on the already created old assessment materials or the textbook based assessment and instructional materials. When no assessments are available, teachers construct assessments on their own, which may not be in line with the standard assessment criterion and that may lack proper substance.

This is a universally common experience among students that, the uncertainty about the topic on which they will be assessed. They may have prepared themselves on a major assignment but teacher chooses a different one for assessment. As a result, students regard formal assessment as a matter of anticipation on which they do not have any control. Therefore, there is possibility of negative washback effect in a foreign language classroom. " $A$ poor test may be associated with positive effects and a good test with negative effects because of other things that are done or not done..." (Messick, 1996: 242).

\section{Challenges Surrounding Assessment Practices}

Although assessment is one of the most important factors affecting students' learning, it continues to be misunderstood or poorly understood especially with regard to the following perspectives (Biggs, 1999): the persistent incongruence between curricular and assessment purposes; the purpose of assessment methods (formative/summative); and the effect of personal influences. In addition to these, there are some indigenous complexities aroused due to the effect of local culture.

\subsection{Assessment Purpose}

Formative assessments serve feedback related purposes such as diagnosis, prediction, and evaluation of teacher and student performance (Black \& Wiliam, 1998). However, a test that was designed to give formative feedback is only formative if the teacher uses it to provide feedback for the student. Researchers however argue, Saudi students do not think highly of the feedback, and that the feedback they desire is markedly different from what they receive (Mustafa \& Rami, 2012). Another challenge of formative assessment is the alignment of assessment purposes (including feedback) with the course objectives. Crooks (1998) warned against the possible incongruence between academic objectives as intended by the curriculum and the objectives defined through the assessment process. Synchronization between these two types of objectives is crucial for the teacher-educators.

\subsection{Assessment Influences}

The accuracy and adequacy of assessment tools used to gather information on academic progress and issues related to interpretation of the data are subject to different influencing variables. Influencing factors like culture, environment and others (e.g., offensiveness of materials; level of students' acculturation; behavioral issues, context or perspective) affect students' ability to do well on assessment (Demmert, 2005). In Saudi Arabia, it is a formidable challenge by its own merit to make the unmodified non-indigenous educational approaches acceptable, especially when those approaches are tied to a Western identity. When a non-indigenous approach conflicts with the local standard, such approach will be exterminated at its infancy. (Alabdelwahab, 2002). So, it can easily be understood that, it's a critical challenge for the classroom-teachers to avoid any conflict of purposes.

\subsection{Assessment Washback Effects}

The term 'wash back' or 'backwash' has been used to refer to the way an assessment affects teaching materials and classroom management (Hughes, 1989). One assumption is that teachers will be influenced by the idea that their students are planning to take test (large-scale academic assessment) and will adapt their teaching methods and content to reflect the test demands. Students on the other hand, can do the same and study in accordance with the test requirements. Washback effect is strongly present in Saudi EFL classroom as students and teachers tend to focus heavily on testing criteria. Washback can be positive or negative but this will definitely mislead the assessment purpose.

\subsection{Challenges of Empowering Students}

Another assessment challenge has risen due to the paradigm shift of assessment purpose from mere learning to taking responsibility of learning and assessing on the part of the learners. Students themselves need to develop the capacity to assess their own learning and that of others so that they become continuing learners (Boud, 2010). 
This can be attained by developing assessment tasks that will focus on students' engagement with the content and procedure of learning. The purpose of assessment should be to develop students' critical faculty that will lead to learning-critiquing and continuous learning. Instead of developing as passive recipients of grades, students should become autonomous who can think and act like teachers and actively construct knowledge (Brubaker, 2010). Learning has to be done by the learners, and nobody else can do it for them. Therefore, the more the learner is in control, the more likely that there will be involvement effort for learning. Assessment that takes away control from the learners undermines intrinsic motivation and leads to 'surface' learning (Deci \& Ryan, 1985).

\subsection{Conventional Grading Sysytem of Large-Scale Summative Assessment}

Summative assessment takes place to measure the level of success or proficiency at the end of a unit or academic session comparing it against some standard or benchmark. The purpose is to summarize the learning that had taken place in order to grade or award academic progress. Large-scale (high stake) summative assessments are used for making decisions that affect the future of students, teachers or institutions. The widespread use of summative assessments is supported by range of arguments. Proponents claim, summative assessments cause students, teachers and educational institutions to put more effort into their work for rewards or penalties that can be applied on the results or grades. However, the question is, whether this kind of extrinsic motivational factor (grades) really help students learn or they are to have any negative effect on real learning? While opposing the traditional viewpoint Kohn (1993), pointed out: associating a particular behavior with a reward decreases the likelihood of the behavior being continued voluntarily if not again rewarded. Other opposing viewpoints, which can challenge the conventional utilization of grading, are as the following: Large-scale assessment procedure promotes an authoritarian atmosphere in the classroom and in the society at large. Students, as their future depends on the success and failure of these assessments accept the authority. According to Kohn (2004) grading is a construct more closely aligned to the authoritarian attributes of transmission teaching than with democratic ideals. A growing body of research illustrates the insidious ways teachers resort to grades to maintain control of students (Pace \& Hemmings, 2006). Due to the authoritarian nature of grades, it can easily exert pressure on the students and divert the focus from actual learning to some simulative behavior through memorization, which is a major concern for Saudi EFL classroom. Rugh (2002) pointed out; rote memorization of basic texts continues to be a central feature of much of the educational system of Saudi Arabia even today.

It is argued that, tests and grades motivate only few students and increase the gap between higher and lower achievers. Students receiving lower grades can be subject to psychological pressure that can lead to lower self-esteem. Crooks (1998) looked at the impact of summative assessment on students, and concluded that test anxiety has a crippling effect on the students and that this could be reduced by avoiding comparisons between students and the use of letter grades. Summative assessments motivate students to acquire performance goals that are associated with grades and scores rather than learning goals. Kellaghan et al. (1996) expressed doubts that high stakes testing through traditional grading system is compatible with the aims of education reform. According to him, they only activate the mechanism of attaining certain academic fit represented by grades. Proponents of large-scale assessments will argue that, right kind of tests will lead to attainment of learning goals. However, this argument underestimates the ability of test preparation to corrupt the very essence of the learning goals. Therefore, it is time to counter students' deeply rooted familiarity with conventional grading systems. Otherwise, Brubaker warned: consequences of upholding the statuesque are too harmful to continue to justify. (2010: 266).

\section{Portfolio as an Assessment Practice}

Portfolios are collection of students' work (task response) with an objective of recording progress and induce reflection. Portfolios are procedures that require students keep a record of their academic work in a box or folder to be assessed and commented on by instructors and peers (Brown, 2005). The focus of portfolio assessment is more on awareness and autonomous learning than on language structure. Three basic stages of portfolio assessment as recommended by Hamp-Lyons and Condon (2000) are collection and selection of student's work then reflection on the learning process.

Samples of students' work (collection) - Selecting sample for feedback (selection) - Instructor \& Peers' feedback (evaluation) - Self-evaluation \& correction (reflection).

Portfolio assessment (PA) measures students' progress individually, which is fundamentally different from the traditional norm of assigning grades on a unified single standard. A writing task portfolio is a purposeful collection of students' text that record students' effort and progress over a period of time (Weigle, 2007). Portfolio assessment can be executed either "holistically" or "analytically" (Apple \& Shimo, 2004: 54). Holistic 
assessments consider portfolio as a single measurable unit of preset criteria (which this study intends to focus) and analytic assessments focus on these criteria separately by allocating grades on each item. The most crucial point about the portfolio assessment is, it is not about the quality of writing rather about the process of development and awareness. Portfolio assessments are assumed to promote greater understanding about what good writing is and how to achieve those skills to be good writer (Hyland, 2002). Unlike traditional examination portfolio assessments monitor progress towards an objective over a period of time and the objective is set forward by teacher and students at the beginning of the couse.

\section{Formative Role of Portfolio Assessment on Writing Performance}

During the constructivist post method era there has been a shift of focus from traditional values of teaching and evaluation to a more democratic, student centered productive learning environment. The advocates of these newly found understandings propagate formative assessment as more authentic technique that can effectively align the learning process with the curriculum objectives. Tim McNamara (2000) highlights and stresses on the need for a 'constructive' relationship between teaching and learning. Formative assessment ideally upholds this value by performing a formative role in teaching-learning situation. In this condition, assessment is characterized by teacher-students' interaction based on their learning needs and adjustment towards a better understanding of the teaching contents (Black \& William, 1998). Interactions in the form of feedback are utilized to bridge gap between the actual level and the expected standard specified in the curriculum objectives. Assessment of this sort can cater to varied needs of diverse learner-groups through the use of differentiated teaching where every individual is taught and assessed at the same time based on their need and progress on the ladder of learning.

Portfolios are different as assessment techniques, because students receive ongoing feedback for each of their writing samples, which is characteristically formative. Portfolios as formative assessment techniques are utilized to assess writing samples that learners produce over a defined period of time. Lam and Lee (2009) while highlighting on the formative nature of portfolio assessment showed how it could relate teaching to assessment. Their research demonstrated the majority students' positive attitude towards portfolio assessment. Portfolio assessment can foster learner's reflection by providing opportunity to engage in reflective dialogue with oneself. Fink (2004) believes this kind of reflective learning is supposed to make students more mindful and aware of their own learning. Little (2005) in a study showed how portfolio can play an important role in implementing reflective autonomous learning.

\section{Literature Review}

During the 1980s, portfolio based writing assessment has emerged owing to growing dissatisfaction with the timed-impromptu writing test. The traditional productoriented writing assessment was considered to be outdated while process-oriented formative writing assessment became increasingly prevalent (Hedgcock, 2005). Growing body of researchers started to believe that, it is unnatural that the learners should write composition based on which they will be graded (Cohen, 2001). Subsequently, a standard shift with the nature of writing assessment occurred. By 1990s, the portfolios have gained popularity as viable means of assessment which can effectively replace traditional multiple-choice test and timed extempore essay test (Hamp-Lyons, 2001). Various studies (Gelinas, 1998' Song \& August, 2002) focused on the question of validity and reconfirmed portfolio assessment as a valid instrument. As for the impact and formative nature of portfolio assessment following research was reviewed.

Black and William's (2009) theory of formative assessment highlighted on the regulation of learning and formative feedback in the context of learner-centered pedagogy. Formative feedback initiates scheduled or unprompted classroom interactions which scaffold student learning (Wiliam, 2011). Perrenoud (1998) stressed on this issue of written feedback and pointed out, formative assessment is not only limited to constructivist approach to teaching rather it is focused on the intention to regulate learning through revisable written feedback. It is considered, constructive feedback is the key construct of portfolio assessment. Similarly, the effectiveness of portfolios depends on how efficiently teachers and learners utilize feedback with a view to make the assessment formative. Song and August (2002) demonstrated how portfolio assessment accommodate and support the revision process which according to them can be utilized to monitor progress over a period of time. In portfolio assessment revision process is followed by teacher and peer feedback. Reiterating this point Hamp-Lyons (2007) stated, portfolio assessment has the potential to encourage learning and assessment concurrently by formatively assessing with feedback and summatively evaluating their writing with grades. Arslan (2014) reported portfolios can be instrumental in integrating feedback practices into writing class. His report indicated how portfolios improve students'understanding on various sub-skills of writing. In an empirical study, Nezakatgoo (2011) demonstrated the effectiveness of portfolio by comparing two groups of students' grades. His study showed, 
students whose writing classes were assessed by portofilios had improved significantly in their writing skill.

Chambers and Leah (2007) stated, portfolio assessment helped students recognize their individual learning process. Aydin (2010) found that, the 204 participants perceived they had improvement in grammatical knowledge and writing skills after using portfolio assessment. However, they felt uninterested and preoccupied while dealing with their portfolios due to the fact that they largely followed the procedures set by their instructors without having ownership in conveying their opinions. If students are allowed to submit their preferred piece of writing in a self-selected medium, they are more willing to showcase their expertise and consequently, develop ownership in learning (Siu, 2013). Although students are not involved in making major decisions like program structure, they may participate in minor decision-making processes. So that they can increasingly develop ownership when developing portfolios (Yin, 2014).

Yurdabakan and Erdogan (2009) in their study examined students' perception about portfolio assessment. They concluded that students in general consider portfolio as a fair assessment tool that has the potential to motivate students. EFL learners with a portfolio assessment would result in a satisfactory performance on EFL expository-writing (Dahviyanti \& Iskandar, 2019). We can refer to the findings of previous studies (Wang \& Liao, 2008; Tabatabaei \& Assefi, 2012; Roohani \& Taheri, 2015) which stated, using portfolios did have significant impact on ELF students' writing performance. Contreras-Soto, Véliz-Campos and Véliz (2019) Study conducted in Chile on the research question whether sixth grade students' levels of test anxiety could be reduced through the use of portfolio assessments. Their data analysis revealed portfolios contribute to the lowering of students' test related anxiety.

Similar to other instructional approaches, portfolios assist learning and assessment purpose almost concurrently. Because of their pedagogical importance, portfolio is believed to be a significant form of assessment for learning material (Klenowski, 2010). Since feedback and self-reflective revision are two core components of portfolio approach, the application of assessment as learning ( $\mathrm{AaL}$ ) is spontaneous with formative portfolio assessment (FPA). Portfolio is also considered to be the major form of non-traditional alternative assessment which has strong formative purpose (Fox, 2017).

\section{Statement of the Problem}

Learning and teaching of writing skills are a challenging task for most teachers and students, as writing involves mastering and implementation of lexical, grammatical and syntactic skills. Traditionally, writing assessments have solely focused on the task-end written products where teachers dominated the process as active examiners whereas, students played the role of passive test-takers. Assessments of this type are mainly characterized by administrative requirements where students are assessed to prepare for the summative assessments hurdles. Such assessment being more reflective (focus mainly on observation and evaluation) rather than progressive bears little significance in the field of teaching and learning. Formative assessment on the other hand focuses more on task achievements through inquiry and feedback. Portfolio assessment as a practice of formative assessment has a conceivable advantage due to its learner-centered integrated characteristic. Formative portfolio assessment (FPA) has a potential to encourage autonomous learning among students by motivating them to improve writing performance. However, portfolio assessment (PA) itself as a technique requires to be investigated as to see how far it is effective as a formative assessment tool in a writing classroom.

\section{The Present Study}

There is scarcity of research on the effectiveness of formative portfolio assessment (FPA) on students writing performance. Furthermore, there has been little research on the students' perception about portfolio assessment techniques. This pilot study is an attempt to examine the impact of applying formative assessment techniques on improving students' writing performance.

1) Does formative portfolio assessment affect EFL learners' overall achievement in guided writing tasks?

2) What are students' perception about the use of portfolio assessment?

\section{Methodology}

\subsection{Participants}

The participants of this study were 40 (20 male \& 20 female) undergraduate EFL students at King Khalid University. They were entry-level students at the university receiving their preparatory English language lessons. At the beginning they were given a short writing test (diagnostic), matched, and grouped according to their writing skill ability. Group A of twenty students was our experimental group whereas group B of twenty students was the control group. 


\subsection{Research Design}

The design of the study was limited and experimental. We had a control group and an experimental group. Each group was given a pre-test and post-test in the form of a pre-designed essay-writing task. The independent variable was the portfolio assessment that was applied as an assessment technique among the experimental group. The dependent variable was students' writing ability measurable through a scoring rubric. Independent-sample T-test was utilized to find out if there were any differences between students' performance before and after the implementation of the procedure. Themes emerged from these statistical procedures were discussed with the participants to further gather qualitative data.

\subsection{Research Instruments}

The instruments used in this study were a writing test and interviews. The writing test was to assess students' performance on a guided writing task. Interviews were conducted to find out students' opinions about the impact of portfolio assessment on their writing ability. The interviews were semi-structured and conducted in English. The objective of the interviews was to elicit qualitative data that can reaffirm the quantitative data findings.

\subsection{Procedures}

At the start of the study, the experimental group received detail explanation of the purpose and condition of portfolio assessment. Later they were asked to write different writing compositions in the form of a guided writing task (i.e. example write a short essay about your last trip to a beautiful place, include information like where did you stay and how one can go there?). Having received the first draft of the composition, teacher provided suggestions and written feedback on their writing task highlighting weaknesses. Students were asked to reflect on their errors and how to improve their writing ability. They were also asked to comment on and receive feedback from their peers. Students preserve the first draft in their portfolio as a record and point of reference for future writing samples. As a homework, students wrote the second draft bearing in mind the teacher's and peers' feedback with a view to work on their weaknesses. They revised, redrafted (each time revisiting their earlier portfolio samples) and finally submitted their second and third drafts.

The control group on the other hand, went through traditional classroom learning and assessment. Instructors explained the structure of the essay, how to construct a thesis statement, develop the body paragraphs and finally draw a conclusion. Students were asked to write on different guided writing topics, and they were evaluated (in terms of grades) based on their writing sample. Unlike the experimental group, they were not asked to reflect, redraft, peer-assess or keep a record of their writing. Both group of students were asked to submit their final drafts of their writing samples. The assessment process was made clear to the students before the final submission. Writing drafts checking rubric had four criteria (Appendix A) based on which they were evaluated on a scale of 20 points (each having a maximum 5 points).

\subsection{Results}

The focus of the study is to investigate the effect of formative assessment on students' writing ability. Two research questions were set as part of the study to find out the impact. In order to examine those above mentioned research questions, the following null hypothesis was set forward.

1) Portfolio assessments do not have any impact on ELF students' writing ability.

To inspect the above-mentioned hypothesis, both descriptive and inferential statistical analyses were utilized. In order to investigate the null hypothesis, independent samples t-test was used using SPSS 13. To test the second research question, we interviewed six students (male \& female) to record their perceptions about the impact of portfolio assessment. To investigate the general writing performance between two groups (control \& experimental) in the post test writing phase, independent sample t-test was conducted on SPSS 13. Table 1 shows the mean scores of control group is 11.60 whereas the mean score of experimental group is 15.12.

Table 1. Group statistics

\begin{tabular}{lllll}
\hline Groups & $\mathrm{N}$ & Mean & Std. Deviation & Std.Error Mean \\
\hline Post test Scores Control & 20 & 11.6000 & 1.08337 & .24225 \\
Experimental & 20 & 15.1250 & 1.33648 & .29885 \\
\hline
\end{tabular}

The table below shows; the $\mathrm{p}$ value .00 is lower than .05 which demonstrates that, the mean value between the 
means is statistically significant. Therefore, the null hypothesis that portfolio assessment does not have any impact on ELF students' writing assessment is overruled. Therefore, it can be said, portfolio assessment has an effect on students' writing achievement. Here in this case, students' achievement was improved by implementing portfolio assessment.

Table 2. Independent sample test

\begin{tabular}{llllll}
\hline & \multicolumn{2}{l}{ Levene's Test for Equality of Vairances } & \multicolumn{3}{c}{ t-test for Equality of Means } \\
\hline Posttest scores & $\mathrm{F}$ & Sig. & $\mathrm{T}$ & $\mathrm{Df}$ & Sig. (2-tailed) \\
Equal variances assumed & 1.033 & .316 & -9.163 & 38 & .000 \\
Equal vairances not assemed & & & -9.163 & 36.440 & .000 \\
\hline
\end{tabular}

\subsubsection{Results of Qualitative Data}

The study collected students' opinions about portfolio assessment to attain a contextual understanding of this kind of assessment. Interviews were conducted at the end of the treatment. Eight students (four with higher grades and four with lower writing grades) male and female of equal ratio were interviewed. The duration of the interview varied between fifteen to twenty minutes depending on the situation. In some cases, students answered in their native language, which were recorded and later translated into English. After careful inductive analysis of students' opinions, we identified few recurring themes that emerged out of student and teacher talk.

Most of the students in the experimental group mentioned that they have the feeling; portfolio assessment treatment has improved their writing in general. Students unanimously expressed their satisfaction in the assessment process. One student (male) said:

"I enjoyed the portfolio writing assessment session. It was very different from other writing classes. I felt more inspired in writing and enjoyed checking my friends' essays." (M1)

Students opined portfolio assessment is more motivating and engaging. They felt responsible for what they are writing and participated in the lively discussion after writing assessment sessions. In question of which specific aspect of assessment do they think was most effective? They replied collectively, the after writing assessment session. One student (female) in particular said:

"I liked the fact that teacher took extra care in correcting our mistakes and I think it was very effective...... I also like the step by step process of assessment activities" (F1)

Few students specifically stated the importance of revision stage (reproduction) in the total writing process. They said, the revision or reflecting on their own writing was very crucial. At the same time, they witnessed other writing examples (of their peers) which pointed out where to focus on their own writing skills to improve. "To me the review parts of the assessment process were very important as they helped to develop my writing" (M2). Another student said: "at the discussion stage... I understood my errors and tried to improve in the next draft of writing" (F2). Students in general perceived the importance of reproducing writing samples in gradual process of correction under portfolio assessment. The same student (Female) pointed out:

"Keeping a record of my own writing samples with corrections and comments by teacher and students was important. I used to look at my previous samples to write the next sample" (F2)

Another recurring theme emerged out of the interview is that, the lasting impact of portfolio assessment on students' future academic writing. Practice of portfolio assessment encourage students' reflection on their own learning process (Lynch \& Shaw: 2005). As one student stated: "I will try to focus on grammar and vocabulary of writing more and will ask for help from my teachers" (M3). This showed students were thinking independently of their errors and corrections like autonomous learners as another student (Male) mentioned: "I think I have to concentrate more on reading that will help me be a better writer". Few students tried different learning tools made-up their own like using dictionary and grammar books more, which is an evidence of autonomous learning. Students in general felt more responsible towards the learning process, as they believed that, they owned the assessment tool, and they can utilize them for their betterment.

\section{Discussion \& Recommendations}

The present study examines the impact of formative portfolio assessment on students' overall writing ability. The result of the research showed, FPA affected students' writing achievement in general. The outcomes reflect the 
findings of other similar kind of studies. It is consistent with the study by Caner (2010) who investigated Turkish ELF students' performance utilizing portfolio assessment. He reported, while students preferred traditional paper pencil tests as summative assessment tool students unanimously testified their belief that portfolio assessment contributed to their learning. In a more recent study by Obeiah et al. (2016) demonstrated that portfolio group outperformed the conventionally instructed groups. They were investigating tenth grade learners' overall writing performance by using portfolios. The findings are also in consistent with the research findings of Lam and Lee (2009) whose study in Hong Kong university clearly indicates that students hold positive attitude towards the formative aspects of portfolio assessment.

Throughout the study, students felt motivated and at ease with the learning process. The level of learner anxiety in the class (experimental group) was considerably low. This is a significant indicator for portfolio assessment to be effective in a writing class because it is believed that "the fear of writing process outweighs the projected gain from writing" (Thompson, 1980: 121). However, this fact of relatively lower learner-anxiety with portfolio assessment was stated in a study by Öztürk and Çeçen (2007) who showed, portfolio assessment has the potential to reduce learner-anxiety in ELF writing class. The ample time allocated in the process of portfolio making let students to get prepared and present their writing samples. This practice gradually reduces their anxiety level that may stem from the fear of being assessed by peers. Moreover, frequent contact between teacher and students can diminish anxiety and trigger effective communication between two parties. (Barton \& Collins, 1997)

With the help of portfolios, students see the tangible outcome of their efforts that eventually leads to a solid sense of accomplishment. Portfolio record of their progress can be instrumental to boast confidence, which is evident in some of the students' speech. This finding is in line with the finding of Slovin (2001) who investigated students' writing achievement using portfolios. His study found, portfolios gave students' a degree of confidence by promoting their motivation and autonomy. In another study, Wang and Liao (2008) investigated whether portfolio assessment had any positive effects on students writing performance. The overall result showed, students under portfolio assessment had greater performance and satisfaction.

The findings of our study suggest that, students perceive formative portfolio assessment (FPA) as an effective tool over their learning hurdles. Furthermore, the findings pinpoint to the crucial role of the teachers to make portfolio a success. Based on our study following recommendations are made with which teachers can increase the formative potential of portfolio assessment.

i. Teachers can promote greater sense of ownership and autonomous learning among students. They can encourage informed learner-choice in writing class, first by explaining and later encouraging students to make decisions in the learning process.

ii. It is important for the teachers to focus on the formative techniques of portfolio assessments. Great deal of attention should be given on review and discussion sessions.

iii. Teachers should develop a detail portfolio scoring rubric (grade descriptors) for the purpose of formative and course-end summative assessment. Otherwise, the reliability of the assessment will be in question.

iv. Managing a bulk of portfolios can be challenging task for the teachers. Therefore, teachers should organize a well thought out course plan keeping enough time for feedback, counseling and reflective re-writing by the students.

v. Portfolios as assessment techniques should be included in teacher education programmes to avoid any misunderstanding on the part of the teachers.

\section{Conclusion}

There is no doubt that portfolios can be a significant learning and assessment approach for writing skill of English language learners. As the findings of this study revealed, there are statistical differences in students' performance and level of motivation between the control group and experimental group. However, there are several limitations to the present study. Age, gender and other affective factors are left out in the present study that could be dealt with in further study. Nevertheless, formative portfolio assessments help students identify their metacognitive strategies while learning and reflecting about their process of learning. As opposed to the authoritarian characteristic of course end summative assessment, teachers have to play the role to promote formative assessment and "portfolio assessment can go a long way towards balancing the summative and formative functions of writing assessment" (Lam \& Lee: 2009, p. 62). Together with students, teachers have to re-conceptualize the very nature of learning and assessment. As Shor \& Freire argue, doing so is essential for fostering a different social order: "If teachers or students exercised the power to remake knowledge in the classroom, then they would be asserting their power to remake society" $(1987$, p. 10) 


\section{References}

Alabdelwahab, S. Q. (2002). Portfolio assessment: A qualitative investigation of portfolio self-assessment practices in an intermediate efl classroom, Saudi Arabia. Ohio State University.

Alhareth, Y. A., \& Dighrir, I. A. (2014). The Assessment Process of Pupils' Learning in Saudi education system: A Literature Review. American Journal of Educational Research, 2(10), 883-891. https://doi.org/10.12691/ education-2-10-6

Alsadaawi, A., (2010). Saudi national assessment of educational progress (SNAEP), International Journal of Education Policy and Leadership, 5(11), 1-14. https://doi.org/10.22230/ijepl.2010v5n11a202

Apple, M., \& Shimo, E. (2004). Learners to teacher: Portfolios, please! Perceptions of portfolio assessment in EFL classrooms. Proceedings of JALT pan-SIG Conference (pp. 53-58). Tokyo Keizai University.

Arslan, R. (2014). Integrating Feedback into Prospective English Language Teachers' Writing Process via Blogs and Portfolios. The Turkish Online Journal of Educational Technology, 13(1), 131-150

Aydin, S. (2010). EFL writers' perceptions of portfolio keeping. Assessing Writing, 15(3), 194-203. https://doi.org/10.1016/j.asw.2010.08.001

Barton, J., \& Collins, A. (1997). Starting out: Designing your portfolio. In J. Barton, \& A. Collins (Eds.), Portfolio assessment: A handbook for educators (pp. 1-10). New Jersey: Dale Seymour Publications.

Biggs, J. (1999). Teaching for quality learning at university. Buckingham: SRHE and Open University Press.

Birenbaum, M., \& Feldman, R. (1998). Relationships between Learning Patterns and Attitudes towards Two Assessment Formats. Education Research, 40(1), 90-98. https://doi.org/10.1080/0013188980400109

Black, P., Harrison, C., Lee, C., Marshall, B., \& Wiliam, D. (2004). Working inside the black box: Assessment for learning in the classroom. Phi Delta Kappan, 86(1), 8-21. https://doi.org/10.1177/003172170408600105

Black, P., \& William, D. (1998). Inside the Black Box: Raising Standards through Classroom Assessment. Phi Delta Kappan international, 80(2), 139-148.

Black, P., \& Wiliam, D. (2009). Developing the theory of formative assessment. Educational Assessment, Evaluation and Accountability, 21(1), 5-31. https://doi.org/10.1007/s11092-008-9068-5

Bloom, B.S. (1969). Some theoretical issues relating to educational evaluation. In R. W. Taylor (Ed.), Educational evaluation: New roles, new means: The 68th yearbook of the National Society for the Study of Evaluation, Part II (pp. 26-50). Chicago: University of Chicago Press.

Boud, D., \& Associates (2010). Assessment 2020: Seven propositions for assessment reform in higher education. Sydney: Australian Learning and Teaching Council.

Brown, D. J. (2005). Testing in language programs: A comprehensive guide to English language assessment. New York: McGraw-Hill Companies, Inc. https://doi.org/10.1191/02655322051t306xx

Brubaker, N. D. (2010). Negotiating Authority by Designing Individualized Grading Contracts. Studying Teacher Education: A journal of self-study of teacher education practices, 6(3), 257-267. https://doi.org/ $10.1080 / 17425964.2010 .518667$

Caner, M. (2010). Students views on using portfolio assessment in EFL writing courses. Anadolu University Journal of Social Sciences, 10(1), 223-236.

Chambers, S. M., \& Leah, E. W. (2007). The Electronic Portfolio Journey: A Year Later. Education, 127(3), 351-360.

Cohen, A. D. (2001). Second language assessment. In M. Celce-Murcia (Ed.), Teaching English as a Second Language (pp. 513-534). Boston: Heinle \& Heinle.

Contreras-Soto, A., Véliz-Campos, M., \& Véliz, L. (2019). Portfolios as a Strategy to Lower English Language Test Anxiety: The Case of Chile. International Journal of Instruction, 12(1), 181-198. https://doi.org/10.29333/iji.2019.12112a

Crooks, T. J. (1998). The impact of classroom evaluation practices on students. Review of Educational Research, 58, 438-81. https://doi.org/10.3102/00346543058004438

Dahviyanti, W. N. G., \& Iskandar, I. (2019). Using portfolio assessment to improve EFL students' expository-writing performance. International Journal of Humanities and Innovation (IJHI), 2(1), 1-12. https://doi.org/10.33750/ijhi.v2i1.29 
Deci, E., \& Ryan, R. (1985). Intrinsic motivation and self-determination in human behavior. New York, US: Plenum. https://doi.org/10.1007/978-1-4899-2271-7

Demmert, W. G. Jr. (2005). The Influences of Culture on Learning and Assessment Among Native American Students. Learning Disabilities Research \& Practice, 20(1), 16-23. https://doi.org/10.1111/ j.1540-5826.2005.00116.x

De Silva, R. (2014). Rubrics for assessment: Their effects on ESL students' authentic task performance. Center for English language communication 4th symposium proceedings.

El Ebyary, K. (2013). Profiling Formative Assessment Culture in EFL Teacher Education Programs in the Middle East. Theory and Practice in Language Studies, 3. https://doi.org/10.4304/tpls.3.12.2169-2177

Fink, L. D. (2004). Learning Portfolios: A Powerful Tool for Enhancing Course Design, in J. Zubizarreta, The Learning Portfolio: Reflective Practice for Improving Student Learning (Association of Supervision and Curriculum Development; Alexandra, VA).

Fox, J. (2017). Using portfolios for assessment/alternative assessment. In E. Shohamy, I. G. Or, \& S. May (Eds.), Language testing and assessment, Encyclopedia of language and education (3rd ed., pp. 135-148). Dordrecht, The Netherland: Springer. https://doi.org/10.1007/978-3-319-02261-1_9

Gelinas, A. (1998). Issues of validity and reliability in using portfolio assessment to measure foreignlanguage teacher performance. Unpublished doctoral dissertation, The Ohio State University.

Hamp-Lyons, L., \& Condon, W. (2000). Assessing the portfolio: Principles for practice, theory, and research. Cresskill: Hampton Press.

Hamp-Lyons, L. (2001). Fourth generation writing assessment. In T. Silva, \& P. K. Matsuda (Eds.), On Second Language Writing (pp. 117-128). Mahwah, NJ: Lawrence Erlbaum.

Hamp-Lyons, L. (2007). The impact of testing practices on teaching: ideologies and alternatives. In J. Cummins, \& C. Davison (Eds.), International handbook of English language teaching (pp. 487-504). Norwell, MA: Springer.

Hedgcock, J. S. (2005). Taking stock of research and pedagogy in L2 writing. In E. Hinkel (Ed.), Handbook of Research in Second Language Teaching and Learning (pp. 579-614). Mahwah, NJ: Lawrence Erlbaum.

Hyland, K. (2002). Teaching and researching writing. Pearson Education: London.

Hughes, A. (1989). Testing for language teachers (p. 172). Cambridge and New York: Cambridge University Press.

Kellaghan, T., Madaus, G., \& Raczek, A. (1996). The use of external examinations to improve student motivation. Washington DC, US: AERA.

Klenowski, V. (2010). Portfolio assessment. In P. Peterson, E. Baker, \& B. McGaw (Eds.), International encyclopedia of education (3rd ed., pp. 236-242). Oxford, UK: Elsevier. https://doi.org/10.1016/ B978-0-08-044894-7.00315-8

Kohn, A. (1993). Punished by rewards. Boston, US: Houghton Mifflin. https://doi.org/10.1097/00019514199412000-00011

Kohn, A. (2004). What does it mean to be well educated? Boston, MA: Beacon Press.

Lam, R., \& Lee, I. (2009). Balancing the dual functions of portfolio assessment. ELT Journal, 64(1), 54-64. https://doi.org/10.1093/elt/ccp024

Little, D. (2005). The common European framework and the European language portfolio: Involving learners and their judgments in the assessment process. Language Testing, 22(3), 321-336. https://doi.org/10.1191/ 02655322051t311oa

Lynch, B., \& Shaw, P. (2005). Portfolio, power and ethics. Tesol Quarterly, 39(2), 263-297. https://doi.org/ $10.2307 / 3588311$

McNamara, T. (2000). Language Testing. In H. G. Widdowson (Ed.). Oxford Introductions to Language Study. Oxford University Press.

Messick, S. (1996). Validity and washback in language testing. Language Testing, 13(4), 241-56. https://doi.org/10.1177/026553229601300302

Mustafa, \& Rami, F. (2012). Feedback on the Feedback: Sociocultural Interpretation of Saudi ESL Learners' 
Opinions about Writing Feedback. English Language Teaching, 3-15. https://doi.org/10.5539/elt.v5n3p3

Nezakatgoo, B. (2011). The Effects of Portfolio Assessment on Writing of EFL Students. English Language Teaching, 4(2) 231-241. https://doi.org/10.5539/elt.v4n2p231

Obeiah, S. F., \& Bataineh, R. F. (2016). The effect of portfolio-based assessment on Jordanian EFL learners' writing performance. Bellaterra Journal of Teaching \& Learning Language \& Literature, 9(1), 32-46. https://doi.org/10.5565/rev/jt13.629

Öztürk, H., \& Çeçen, S. (2007). The effects of portfolio keeping on writing anxiety of EFL students. Journal of Language and Linguistic Studies, 3(2).

Pace, J. L., \& Hemmings, A. (2006). Classroom authority: Theory, research, and practice. Mahwah, NJ. Lawrence Erlbaum Associates. https://doi.org/10.4324/9781410617163

Perie, M., Marion, S., \& Gong, B. (2007). A framework for considering interim assessments. National Center for the Improvement of Educational Assessment, Dover, NH.

Perrenoud, P. (1998). From formative evaluation to a controlled regulation of learning processes: towards a wider conceptual field. Assessment in Education: Principles, Policy \& Practice, 5(1), 85-102.

Roohani, A., \& Taheri, F. (2015). The effect of portfolio assessment on EFL learners' expository writing ability. Iranian Journal of Language Testing, 5(1), 46-59.

Rugh, W. A. (2002). Education in Saudi Arabia: choices and constraints. Middle East Policy, 9(2), 40. https://doi.org/10.1111/1475-4967.00056

Scriven, M. (1967). The methodology of evaluation (Vol. 1). Washington, DC: American Educational Research Association.

Shor, I., \& Freire, P. (1987). A pedagogy for liberation: Dialogue on transforming education. Westport, CT: Bergin \& Garvey. https://doi.org/10.1007/978-1-349-18574-0

Siu, F. (2013). The incorporation of e-Portfolios into five EFL courses - barriers encountered in the diffusion of technology. Journal of Interactive Learning Research, 24(2), 211-231.

Slovin, B. (2001). An analysis of English as a second language (ESL) students' writing experiences as reflected through the portfolio writing process approach. Unpublished doctoral dissertation, Texas A\&M University.

Song, B., \& August, B. (2002). Using portfolios to assess the writing of ESL students: A powerful alternative. Journal of Second Language Writing, 11(1), 49-72. https://doi.org/10.1016/S1060-3743(02)00053-X

Stiggins, R. J. (2002). Assessment Crisis: The absence of assessment FOR learning. Phi Delta Kappan, 83(10), 758-765. https://doi.org/10.1177/003172170208301010

Tabatabaei, O., \& Assefi, F. (2012). The Effect of Portfolio Assessment Technique on Writing Performance of EFL Learners. English Language Teaching, 5(5), 138-147. https://doi.org/10.5539/elt.v5n5p138

Thompson, M. O. R. (1980). Classroom Techniques for Reducing Writing Anxiety: A Study of Several Cases.

Wang, Y. H., \& Liao, H. C. (2008). The application of learning portfolio assessment for students in the technological and vocational education system. Asian EFL Journal, 10(2), 132-154.

Weigle, S. (2007). Teaching writing teachers about assessment. Journal of Second Language Writing, 16(3), 194-209. https://doi.org/10.1016/j.jslw.2007.07.004

Wiliam, D., \& Thompson, M. (2008). Integrating assessment with learning: What will it take to make it work? In C. A. Dwyer (Ed.). The future of assessment: Shaping teaching and learning (pp. 53-82). New York: Lawrence Erlbaum Associate. https://doi.org/10.4324/9781315086545-3

Wiliam, D. (2011). What is assessment for learning? Studies in Educational Evaluation, 37, 3-14. https://doi.org/10.1016/j.stueduc.2011.03.001

Yin, M. (2014). Portfolio assessment in the classroom. In A. J. Kunnan (Ed.), The companion to language assessment (Vol. II, pp. 659-676). Oxford, UK: Wiley. https://doi.org/10.1002/9781118411360.wbcla042

Yurdabakan, I., \& Erdogan, T. (2009). The Effects of Portfolio Assessment on Reading, Listening and Writing Skills of Secondary School Prep Class Students. The Journal of International Social Research, 2(9), 526-538. 


\section{Appendix A}

\begin{tabular}{|c|c|c|}
\hline Standard & Descriptors & Scores \\
\hline \multirow[t]{5}{*}{ Content } & Fully satisfy the the task requirements, includes all relevant details & 5 \\
\hline & Mostly covers the rquirements, includes most of the relevant details & 4 \\
\hline & Addresses some of the requirements, includes some relevant information & 3 \\
\hline & Attempt to address the topic but presents inadequate information & 2 \\
\hline & Answer is incomplete and irrelevant & 1 \\
\hline \multirow[t]{5}{*}{ Organization } & Excellent introduction, body and conclusion. Paragraphing is skillfull \& cohesive & 5 \\
\hline & $\begin{array}{l}\text { 2. Includes introduction, body and conclusion. Uses paragraphing and cohesive } \\
\text { devices }\end{array}$ & 4 \\
\hline & 3. Attempts to maintain appropriate paragraphing. Insufficient supporting details. & 3 \\
\hline & 4. Inappropriate paragraphing, insufficient use of cohesive devices. & 2 \\
\hline & No attempt to maintain cohesion and coherence & 1 \\
\hline \multirow[t]{5}{*}{ Vocabulary } & Uses wide range of vocabulary with appropriate lexical features & 5 \\
\hline & 2. Uses fair range of vocabulary suitable for the audience and purpose & 4 \\
\hline & Uses sufficient range of vocabulary with occasional errors & 3 \\
\hline & 4. Uses limited vocabulary with noticeable errors & 2 \\
\hline & 5. Uses inappropriate vocabulary & 1 \\
\hline Grammar \& & Uses wide range of grammatically correct sentence structures with perfect spelling & 5 \\
\hline \multirow[t]{4}{*}{ Spelling } & Uses variety of correct sentence structures and spellings with occasional errors & 4 \\
\hline & Uses basic sentence structures with some errors of spelling & 3 \\
\hline & Uses limited range of sentence structures frequent errors of spelling & 2 \\
\hline & Uses unrelated sentence fragments with spelling errors & 1 \\
\hline
\end{tabular}

Source: Adapted from De Silva (2014).

\section{Copyrights}

Copyright for this article is retained by the author(s), with first publication rights granted to the journal.

This is an open-access article distributed under the terms and conditions of the Creative Commons Attribution license (http://creativecommons.org/licenses/by/4.0/). 